\title{
Photolysis of 2,4,6-trinitrotoluene in Seawater and Estuary Water: Impact of pH, Temperature, Salinity, and Dissolved Organic Matter
}

\author{
Dianne J. Luning Prak* \\ James E. T. Breuer ${ }^{1}$ \\ Evelyn A. Rios ${ }^{2}$ \\ Erin E. Jedlicka ${ }^{3}$ \\ Daniel W. O’Sullivan ${ }^{4}$
}


The influence of salinity, $\mathrm{pH}$, temperature, and dissolved organic matter on the photolysis rate of 2,4,6-trinitrotoluene (TNT) in marine, estuary, and laboratory-prepared waters was studied using a Suntest $\mathrm{CPS}+{ }^{\circledR}$ solar simulator equipped with optical filters. TNT degradation rates were determined using HPLC analysis, and products were identified using LC/MS. Minimal or no TNT photolysis occurred under a 395-nm long pass filter, but under a 295-nm filter, first-order TNT degradation rate constants and apparent quantum yields increased with increasing salinity in both natural and artificial seawater. TNT rate constants increased slightly with increasing temperature $\left(10\right.$ to $\left.32^{\circ} \mathrm{C}\right)$ but did not change significantly with $\mathrm{pH}(6.4$ to 8.1$)$. The addition of dissolved organic matter (up to $5 \mathrm{mg} / \mathrm{L}$ ) to ultrapure water, artificial seawater, and natural seawater increased the TNT photolysis rate constant. Products formed by TNT photolysis in natural seawater were determined to be 2,4,6-trinitrobenzaldehyde, 1,3,5trinitrobenzene, 2,4,6-trinitrobenzoic acid, and 2-amino-4,6-dinitrobenzoic acid.

Keywords: explosives, ultraviolet radiation, nitrogen compounds, photochemistry 


\section{Introduction}

The explosive 2,4,6-trinitrotoluene (TNT) and its transformation products (photolytic, abiotic, or biotic) are toxic contaminants that have been found in the environment surrounding TNT manufacturing facilities and artillery ranges (Sunahara et al., 2009). TNT and its transformation products enter the marine and estuary environment via runoff from these facilities or from breached, corroded shell casings of unexploded ordnance (UXO). In particular, UXOs pose a large threat to the marine environment because they have the potential to release large amounts of TNT into the environment as the metal casings corrode. Because TNT can be toxic to marine life, Nipper et al. (2009) proposed that the Interim TNT Water Quality Criteria (IWQC) for the protection of marine life should be $0.376 \mu \mathrm{M}$ and $0.125 \mu \mathrm{M}$ for acute and chronic values, respectively, based on a review of the impact of TNT on marine organisms. In order to better understand the impact of TNT on marine environments, the photolytic transformation of TNT, which occurs when TNT is exposed to sunlight near the seawater surface where temperatures range from 5 to $28^{\circ} \mathrm{C}$ for non-arctic environments (Millero, 2006), must be studied. This photolytic transformation may be impacted by the presence of other dissolved species such as ionic substances, hydrogen ions $(\mathrm{pH})$, dissolved organic substances or by temperature. By determining the effect of chemical and physical factors that influence the rate of TNT photolysis, such as salinity, dissolved organic matter concentration, $\mathrm{pH}$, and temperature, the overall impact of munitions on the seawater environment can be quantified.

The presence of ionic substances has been found to both enhance and retard the photolytic transformation of TNT and other nitroaromatic compounds. In general, the photolysis rates of TNT and dinitrotoluenes are faster in seawater than in freshwater, have followed firstorder transformation behavior, and have been impacted by the wavelength of light irradiating the 
sample (Simmons and Zepp, 1986; Celin et al., 2003; Nipper et al., 2004; Mihas et al., 2007; O'Sullivan et al., 2010, 2011; Luning Prak et al., 2013). In both freshwater and seawater, TNT is photolyzed faster than 2,6-dinitrotoluene (2,6-DNT), which in turn is faster than 2,4dinitrotoluene (2,4-DNT), under similar photolysis conditions (Simmons and Zepp, 1986; Luning Prak et al., 2013; O’Sullivan et al., 2010). For individual ions, our laboratory has found that adding nitrate ions to levels normally found in seawater $(<4 \mathrm{mM})$ increased photolysis of TNT, 2,6-DNT, or 2,4-DNT when dissolved in pure water but not when dissolved in seawater, suggesting that the other dissolved substances impact photolysis rates more than added nitrate (O’Sullivan et al., 2011, Luning Prak et al., 2013). An increased hydrogen ion concentration (lower $\mathrm{pH}$ ) was found to lower the photolysis rate of TNT, 2,6-DNT, and 2,4-DNT in ultrapure water, but not change TNT photolysis rates in pond water ( $\mathrm{pH}$ decrease from 8.0 to 4.0), and slightly increase 2,4-DNT and 2,6-DNT photolysis rates in seawater (pH decrease from 8.1 to 6.4) (Burlinson et al., 1979; Mabey et al., 1982, Luning Prak et al., 2013). The complex interplay of hydrogen ion and other ions in photolysis is demonstrated by the result that addition of lithium chloride to TNT solutions reduced its photolysis rate under acidic conditions in methanol (Suryanarayanan and Capellos, 1974). In contrast, the addition of sodium chloride to water around $\mathrm{pH} 7$ increased 2,4-DNT photolysis rates for a 4\% solution with no additional rate increases for $8 \%$ and $15 \%$ solutions (Mihas et al., 2007). Work in our laboratory has shown that increasing the salinity of artificial seawater up to values found in natural seawater increased the photolysis of 2,4-DNT and 2,6-DNT (Luning Prak et al., 2013). A gap in knowledge remains on how salt concentration and hydrogen ion concentration (small range in seawater/estuary water) impact TNT photolysis in seawater. 
Dissolved organic matter (DOM), which includes humic acid, fulvic acid, and hydrophilic acids, can an increase the photolysis rate of nitroaromatic compounds by photosensitization processes or slow the photolysis rate by attenuating the light reaching the compound or by quenching the excited state of the compound being photolyzed (Thurman, 1985; Leifer, 1988; Nima et al., 2016). Simmons and Zepp (1986) found that increasing the humic material added to laboratory waters increased the photolysis of 2,6-DNT. In our laboratory, the addition of fulvic acid to freshwater, artificial seawater, and marine waters enhanced the photolysis of 2,6-DNT, while the addition of DOM to only freshwater and artificial seawater enhanced the photolysis of 2,4-DNT (Luning Prak et al., 2013). Mabey et al. (1983) attributed an enhancement in TNT photolysis rates in natural waters (Holston River in Tennessee, Waconda Bay in Tennessee, and Searsville Pond in California) over rates in distilled water to the presence of humic materials, but they did not quantify the amount of humic material. Quantification of the impact of dissolved organic matter concentration on TNT photolysis rates needs to be determined. Since 2,6-DNT and 2,4-DNT behaved slightly differently when DOM was added, the behavior of TNT needs to be investigated.

Temperature usually has little effect on photochemical processes. Temperature does not generally affect radiative and radiationless decay processes in photochemical reactions, but it can affect primary and secondary chemical processes from the excited state (Baltrop and Coyle, 1975). We found that increasing seawater temperature from 10 to $32^{\circ} \mathrm{C}$ had no impact on the photolysis of 2,6-DNT but did increase the photolysis of 2,4-DNT, resulting in an activation energy of $15 \mathrm{~kJ} / \mathrm{mol}$ (Luning Prak et al., 2013), which falls in the range of 15 to $28 \mathrm{~kJ} / \mathrm{mol}$ reported by Baltrop and Coyle (1975). Since the photolysis of 2,4-DNT was impacted by 
temperature and 2,6-DNT was not, it is not certain how the photolysis of TNT will be affected by temperature in marine waters and needs to be investigated.

Given that many UXOs contain TNT, which can be toxic to marine organisms, the rate of transformation of TNT by photolysis in marine systems needs to be studied. Prior studies suggest that $\mathrm{pH}$ and DOM affect the photolysis rates of TNT in pure water systems, so there is a need to quantify the effects of these factors in marine waters. Other factors such as temperature and salinity should also be studied for marine waters to assess their impact on TNT photolysis. The goal of this study is to determine the impact of $\mathrm{pH}$, salinity, temperature, and dissolved organic matter on the photolysis of TNT in marine and estuary waters, and to isolate and identify some of the photolysis products to determine if the products formed in marine waters are the same as those found in fresh water systems.

\section{Materials and Methods}

\subsection{Materials}

Initially, stock solutions of TNT (227.16 g/mol, Eastman Chemical, > 95\% purity) were prepared in acetonitrile (Baxter Scientific). Aliquots of the stock solutions were then added to ultrapure $18 \mathrm{M} \Omega$ water, artificial seawater, filtered natural seawater, or filtered estuarine water prior to photolysis. The ultrapure $18 \mathrm{M} \Omega \mathrm{cm}^{-1}$ water was generated using a Barnstead E-pure ${ }^{\circledR}$ water system. Seawater was collected from Key West, Florida, the Gulf of Mexico near the Mississippi River, near Charleston Harbor in South Carolina, and near Kahana Bay in Hawaii, and filtered through $0.45 \mu \mathrm{m}$ and $0.22 \mu \mathrm{m}$ Gelman Pal filters in order to sterilize the waters (Leifer, 1988). Estuarine waters were collected from the mouth of the Mississippi River, in Charleston Harbor, SC, near Juneau, AK, and in the Chesapeake Bay near Annapolis, MD, and 
filtered like the seawater. The artificial seawater was prepared from various ionic compounds according to guidelines given by Millero (2006) and described in the Supplementary Material. The Suwannee River Fulvic Acid standard I (1S101F) was used to represent humic materials and concentrations of $5 \mathrm{mg} / \mathrm{L}$ or less were selected as representative values of those found in nature (see specific rationale for concentration selection in the Supplementary Material.)

Stock solutions of potential photolysis products, trinitrobenzene (TNB, Aldrich, 99.9\%), trinitrobenzaldehyde (TNBCHO, Chem Div, 95\%), trinitrobenzoic acid (TNBCOOH, Chem Services, 98.3\%), and 2-amino-4,6-dirnitrobenzoic acid (2A46DNBA, Chem Div, 95\%) were prepared in various solvents such as ultrapure water, methanol, and acetonitrile since they did not all dissolve readily in one solvent. TNB and TNBCHO solutions were diluted into ultrapure water and TNBCOOH and 2A46DNBA were diluted in methanol for chemical analysis.

\subsection{Solar simulator experiments}

Photochemical degradation experiments were conducted on solutions of TNT (from 1.7 $\mu \mathrm{M}$ to $0.09 \mathrm{mM}$ ) in laboratory and natural waters using a Suntest CPS $+{ }^{\circledR}$ solar simulator outfitted with a $1.5 \mathrm{~kW}$ xenon lamp, following previously used methods (O'Sullivan et al., 2010; O’Sullivan et al., 2011; Luning Prak et al., 2012, Luning Prak et al., 2013). Details can be found in the Supplementary Material. Briefly, solutions were placed in 10-cm path length optical cuvettes (Starna Cells Inc, $30 \mathrm{~mL}$ volume), placed vertically in a custom-designed, optically dark, temperature-controlled $( \pm 1 \mathrm{~K})$ cell holder that was fitted with 2-inch square long-pass optical filters (Newport and Edmund Optics) that have nominal 50\% transmission at wavelengths of 295 and $395 \mathrm{~nm}$. Two optical cuvettes were placed under each long-pass filter allowing for duplicate exposures, and a set of cuvettes was covered to block the transmission of light so no 
photolysis could occur, thereby acting as a dark control. All experiments were run at $20^{\circ} \mathrm{C}$, except for the ones investigating the effect of temperature on photolysis. A spectroradiometer (SPR-4002, Luzchem Research, Inc.) was used to determine the overall effective irradiance and effective irradiance transmitted by each long-pass filter, with a correction factor for cell geometry determined using potassium ferrioxalate actinometry (Luning Prak et al., 2012).

Photochemical reactions in natural waters can be modeled according to the following equation:

$$
-\frac{d C}{d t}=\phi I_{o \lambda}\left(\frac{\text { Area }}{\mathrm{V}}\right)\left(1-10^{-\left(A_{w, \lambda}+\varepsilon_{\lambda}[C] b\right)}\right)\left(\frac{\varepsilon_{\lambda}[C] b}{A_{w, \lambda}+\varepsilon_{\lambda}[C] b}\right)
$$

In this equation, $\phi$ is the quantum yield, $\mathrm{I}_{\mathrm{o} \lambda}$ is the measured irradiance at that wavelength, $A_{w, \lambda}$, is the absorbance of the solution without the solute being photolyzed, $\varepsilon_{\lambda}$ is the molar absorptivity of the solute $\left(\mathrm{M}^{-1} \mathrm{~cm}^{-1}\right), b$ is the pathlength ( $\left.\mathrm{cm}\right)$ of the cell, $[\mathrm{C}]$ is the concentration of the solute (M), Area is the area through which the light is transmitted, and V is the volume of the solution being irradiated. In the solar simulator a sample is exposed to a range of wavelengths of light, so the quantum yield cannot be calculated for each wavelength under these experimental conditions. A common approach used under such conditions (Johannessen, and Miller, 2001) is to calculate an apparent quantum yield over the range of wavelengths of interest:

$$
\phi_{\text {apparent }}=\frac{\left[-\frac{d C}{d t}(295 \mathrm{~nm} \text { filter })\right]-\left[-\frac{d C}{d t}(395 \mathrm{~nm} \text { filter })\right]}{\sum_{\lambda=295 n \mathrm{~nm}}^{395 \mathrm{~nm}}\left(\frac{\text { Area }}{\mathrm{V}}\right)\left(1-10^{-\left(A_{w, \lambda}+\varepsilon_{\lambda}[C] b\right)}\right)\left(\frac{\varepsilon_{\lambda}[C] b}{A_{w, \lambda}+\varepsilon_{\lambda}[C] b}\right)\left(I_{o \lambda, 295 \mathrm{~nm} \text { filter }}-I_{o \lambda, 395 \mathrm{~nm} \text { filter }}\right)}
$$

The range of wavelengths from $295 \mathrm{~nm}$ to $395 \mathrm{~nm}$ was selected because O'Sullivan et al. (2011) found that TNT was photolyzed under the 295-nm filter but very little photolysis occurred under the 395-nm filter. The numerator calculates the difference in the rates under the two different long pass filters. The denominator quantifies the difference between the amounts of light 
absorbed under each long-pass filter for photolysis. This approach was taken by Luning Prak et al. (2012) and produces an apparent quantum yield with an error of up to $15 \%$ based on propagating the errors in the various measurements.

The presence of dissolved organic matter can reduce the amount of light absorbed by the reacting compound (shading) and alter the rate of reaction through indirect means (e.g. indirect photoreactions). Shading can be accounted for by using a screening factor $\left(\mathrm{S}^{\prime}\right)$ that can be determined by using the ratio of the last two terms in eq. 1 for a system with fulvic acid to that of the system without fulvic acid.

$$
S^{\prime}=\frac{1}{100} \sum_{\lambda=295 n m}^{395 n m}\left(\frac{\left(1-10^{-\left(A_{w, \lambda}+\varepsilon_{\lambda}[C] b\right)}\right)\left(\frac{\varepsilon_{\lambda}[C] b}{A_{w, \lambda}+\varepsilon_{\lambda}[C] b}\right)}{\left(1-10^{-\left(\varepsilon_{\lambda}[C] b\right)}\right)}\right)
$$

This screening factor will reduce the direct photoreaction. The rate of the TNT photoreaction with fulvic acid becomes

$$
-\frac{d C}{d t}=\text { direct photo reaction rate } \times \mathrm{S}^{\prime}+\text { indirect photoreaction rate }
$$

Since the direct and indirect photoreaction rates are first order with respect to the concentration of the reactant (Leifer,1988), the reaction can be described by the following equation:

$$
-\frac{d C}{d t}=k_{\text {measured }}[C]=k_{d}[C] \mathrm{S}^{\prime}+k_{s}[C]
$$

And the observed rate constant depends on rate constants for the direct and indirect reactions:

$$
k_{\text {measured }}=k_{d} \mathrm{~S}^{\prime}+k_{s}
$$

For each experiment, the solutions were irradiated for a specified amount of time after which a $0.5 \mathrm{~mL}$ sample was taken. The samples were analyzed by HPLC using a modified version of EPA method 8330 (Luning Prak and O’Sullivan, 2006, 2007; Luning Prak et al., 2013). Absorbances of the initial and final product solutions were measured from 200 to $800 \mathrm{~nm}$ 
using an Agilent 8453 UV-Visible spectrophotometer with ultrapure water as the blank. The salinity was determined using a YS1 3200 conductivity meter for all samples. For some samples, the density of the solution was measured and used to calculate the salinity by a correlation given in Millero (2006).

Photolysis products from 25-mL samples were extracted from the aqueous solutions using C-18 SampliQ Sep-Pak (Agilent) extraction cartridge for the TNB and TNCHO and Oasis HLB (Waters) extraction cartridges for TNBCOOH and 2A46DNBA. Then a sequence of solvents (ultrapure water, acetonitrile, and methanol) was then used to elute different fractions of the retained compounds from the solid phase extraction cartridges. The original standards of each compound and the extracts were analyzed using liquid chromatography mass spectrometry (LC/MS). LC/MS analysis was performed on a Varian 320 MS triple quadrapole mass spectrometer equipped with a ProStar UV/Vis detector, Varian 212 LC pumps, and a model 410 autosampler. The mobile phase was $45 \%: 55 \%$ methanol:water with $0.1 \%$ formic acid. Separations were performed on a Pursuit XRs ${ }^{\circledR}$ Ultra 2.8 C-18 column $(150 \times 1.0 \mathrm{~mm})$ with a flow rate of $0.150 \mathrm{~mL} / \mathrm{min}$. Products formed during photolysis were identified by retention time using absorbance at $254 \mathrm{~nm}$ and the characteristic mass fragmentation pattern by negative ion mode atmospheric pressure chemical ionization mass spectrometry. The optimized conditions for the MS/MS analysis including the parent ion captured (Q1) in the first quadrupole and the optimal daughter mass (Q3) formed by bombarding the captured parent ion can be found in the Supplementary Material. 


\section{Results and Discussion}

\subsection{Photolysis experiments}

The exposure of solutions containing TNT to simulated sunlight caused the TNT to disappear. As shown in Fig. 1A, TNT concentration in filtered Charleston seawater decreased upon exposure to light with wavelengths greater than $295 \mathrm{~nm}$, and less than $25 \%$ of TNT remained after 2 hours of exposure. In contrast, $94 \%$ of TNT remained after exposure to wavelengths greater than $395 \mathrm{~nm}$. The photolysis is predominantly caused by the ultraviolet light between 295 and $395 \mathrm{~nm}$. No change was observed for the dark control samples.

The TNT concentration change due to photolysis was modeled as a first-order process:

$$
\ln C=-k t+\ln C_{0}
$$

The rate constant for each reaction, $k$, was determined by linear regression (Excel, 2010) of this $\log$-linearized form of the rate equation where $C$ was the concentration at irradiation time $t$, and $C_{o}$ was the initial concentration. The fits using eq. (7) are good (correlation coefficients greater than 0.99) as demonstrated in Fig. 1B. The rate constants for the photolysis of TNT in various seawaters and estuary waters are given in Table 1 along with the standard error of the slope from the linear regression. Preliminary experiments in the current study with ultrapure water followed the same behavior as found by Mabey et al. (1983), and are described in the Supplementary Material. Based on these data, the apparent quantum yield for the photolysis of TNT in ultrapure water as calculated by eq. (2) is $0.0026 \pm 0.0002$, which falls between the reported values of $0.001(\lambda=253.7 \mathrm{~nm})$ and $0.0027(\lambda=313$ and $366 \mathrm{~nm})$ (Sandus and Slagg, 1972; Mabey et al., 1983). This value was based on the molar absorptivities of TNT in ultrapure water measured herein, which agree with those reported by Mabey et al. (1983) as shown in Fig. 2. 
Small differences can be attributed to differences in the solution in which the TNT was dissolved. Mabey et al. (1983) dissolved TNT in a 10\% acetonitrile in water solution, while the current study used water.

\subsubsection{Impact of $\mathrm{pH}$ and temperature}

In this study, $\mathrm{pH}$ and temperature were varied over the small range of values that might be found in seawater systems. Reducing the $\mathrm{pH}$ from 8.0 to values of 7.1 and 6.4 by the addition trace metal grade $\mathrm{HCl}$ had a minimal impact on the rate of photolysis of TNT in seawater as demonstrated by a slight increase from a rate constant of $0.48 \pm 0.03 \mathrm{hr}^{-1}$ at $\mathrm{pH} 8.0$ to values of $0.55 \pm 0.02$ and $0.55 \pm 0.03 \mathrm{hr}^{-1}$ at $\mathrm{pH} 7.1$ and 6.4, respectively, under the 295-nm long pass filter. Such small impacts have been found for TNT photolysis in pond water ( $\mathrm{pH} 4.0$ to 8.0; Mabey et al., 1983) and for 2,4-DNT and 2,6-DNT in seawater systems (pH 6.4 to 8.1, Luning Prak et al., 2013). It may be that the increase in hydrogen ion concentration is so small that it is not impacting the overall rate of reaction.

The increase in temperature caused an increase in the rate constant of TNT with values of $0.39 \pm 0.06 \mathrm{hr}^{-1}, 0.50 \pm 0.02 \mathrm{hr}^{-1}, 0.58 \pm 0.04 \mathrm{hr}^{-1}$ at temperatures of $9^{\circ} \mathrm{C}, 22^{\circ} \mathrm{C}$ and $32^{\circ} \mathrm{C}$, respectively, under the $295 \mathrm{~nm}$ long pass filter. Using these data, the activation energy, $E_{a}$, of the reaction was estimated by the Arrhenius equation:

$$
\ln \mathrm{k}=-\frac{\mathrm{Ea}}{\mathrm{R}}\left(\frac{1}{\mathrm{~T}}\right)+\ln \mathrm{A}_{0}
$$

where $R$ is $8.314 \mathrm{~J} / \mathrm{mol} \mathrm{K}, T$ is temperature in Kelvin, and $A_{0}$ is the frequency factor (plot given in the Supplementary Material). The calculated activation energy for TNT is $12.4 \pm 0.3 \mathrm{~kJ} / \mathrm{mol}$. This value is similar to the activation energies found for 2,4-DNT photolysis over the same temperature range $(15 \mathrm{~kJ} / \mathrm{mol}$ based on data in Luning Prak et al., 2013) and for several 
photochemical reactions reported by Baltrop and Coyle (1975), 15 to $28 \mathrm{~kJ} / \mathrm{mol}$. The increase in rate constant with temperature is not caused by changes in the absorbance of the solutions. The light absorbed, as given by the denominator in eq. (2), for the lowest temperature solution is approximately $3 \%$ higher than that of the highest temperature solution. This $3 \%$ difference is caused by slight increases in absorbance with temperature increase at lower wavelengths and slight decreases in absorbance with temperature at higher wavelengths. Even with a slight increase in light absorbed, the rate constant at the lowest temperature is still smaller than at the higher temperatures.

\subsubsection{Impact of seawater and salinity on photolysis rates}

Comparison of the TNT photolysis rate constants in seawaters from various sources shows very little difference among the seawaters tested from different locations. For all the seawaters tested, the photolysis rate constant for $0.09 \mathrm{mM}$ TNT is approximately $0.52 \mathrm{~h}^{-1}$ for the 295-nm long pass filter exposure and approximately $0.04 \mathrm{hr}^{-1}$ for the $395-\mathrm{nm}$ long pass filter exposure (Table 1). The seawater samples have similar salinity and similar dissolved organic carbon concentrations for those solutions for which dissolved organic carbon measurements were made. When the lower concentrations of $0.048 \mathrm{mM}$ and $0.023 \mathrm{mM}$ TNT in Key West seawater were photolyzed in this work, they yielded rate constants under the $295 \mathrm{~nm}$ long pass filter of $0.75 \pm 0.02$ and $0.92 \pm 0.03 \mathrm{hr}^{-1}$, respectively. The differences in first order TNT rate constants with differing initial concentration is caused, in part, by differing TNT molar absorptivities in the three solutions. The apparent quantum yields for the $0.023,0.048$, and $0.090 \mathrm{mM}$ solutions are $0.045,0.048$, and 0.050 , respectively, which are not statistically different. A few experiments that were run at very low TNT concentration $(1.7 \mu \mathrm{M}$ TNT) produced apparent quantum yields 
that were within the error of the measurement for the solutions with higher TNT concentrations. The remaining experiments were conducted using the solutions of approximately $0.048 \mathrm{mM}$ TNT to facilitate photolysis product isolation and identification.

Increasing salinity was found to increase the rate of photolysis of TNT. This impact of salinity was tested by using artificial seawater and Key West seawater at different dilutions. The photolysis rate constants for $0.045 \mathrm{mM}$ TNT photolyzed in diluted Key West seawater increased from $0.37 \pm 0.01 \mathrm{hr}^{-1}$ for $\mathrm{S}=8$ to $0.55 \pm 0.04 \mathrm{hr}^{-1}, 0.67 \pm 0.01 \mathrm{hr}^{-1}$, and $0.75 \pm 0.04 \mathrm{hr}^{-1}$ for salinity values of 16,24 , and 32 , respectively (Table 1 ). When comparing these photolysis rates with those in artificial seawater (Table 2), the rate constants are similar and follow the trend of increasing rate constant with increasing salinity. Larger rate constants for higher salinity waters have been found for TNT, 2,6-DNT, and 2,4-DNT, but the impact of salinity has only been systematically studied previously for 2,6-DNT and 2,4-DNT (Nipper et al., 2004; Mihas et al., 2007; O’Sullivan et al., 2010; O’Sullivan et al., 2011; Luning Prak et al., 2013).

The change in the rate of a reaction by the presence of salt ions can be attributed to changes in the activity of the reacting species due to changes in the ionic strength of the solution, and is commonly known as the salt effect (Bronsted and Teeter, 1924; Fowler and Guggenheim, 1960). The primary salt effect can take the following functional form

$$
\log \mathrm{k}=\log \mathrm{k}_{\mathrm{o}}+2 \mathrm{~A} \mathrm{Z}_{\mathrm{a}} \mathrm{Z}_{\mathrm{b}}\left[\mu^{1 / 2} /\left(1+\mu^{1 / 2}\right)\right]
$$
as was used by Suryanarayanan and Capellos (1974). In this equation, $\mathrm{k}$ is the rate constant, A is a constant, $Z_{a}$ and $Z_{b}$ are the charges of the reacting ions, $\mu$ is the ionic strength, and $k_{0}$ is the rate constant at infinite dilution. This equation predicts that if reacting ions are of opposite charge, then the reaction rate constant should decrease in the presence of added salts. The data presented herein do not follow the functional form of eq. (9) or the expected behavior using apparent 
quantum yield as a proxy for k as shown in Figure 3A. Suryanarayanan and Capellos (1974) photolyzed TNT in methanol solutions under acidic conditions at various concentrations of $\mathrm{LiCl}$ and found that the rate of reaction did decrease as $\mathrm{LiCl}$ increased in a manner that followed eq. (9). The authors hypothesized that a TNT anion was reacting with the hydrogen ions according to the reaction below.

$$
\mathrm{H}^{+}+\text {TNT anion }{ }^{-} \rightarrow \text { products. }
$$

Burlinson et al. (1979B) presented a mechanism for the initial photolysis of TNT that shows the formation of an aci-TNT species (hydrogen on the methyl group is moved to a nearby nitro) which is followed by its ionization in polar solvents to form a TNT anion. This TNT anion is likely the one that reacted with hydrogen ions in the work of Suryanarayanan and Capellos (1974) and exhibited the behavior of the primary salt effect. In the current study, the higher $\mathrm{pH}$ would minimize the reaction given in eq. (10), and the TNT anion that is produced by the deprotonation of the aci-TNT species is more likely to be influenced by the secondary kinetic salt effect.

In the secondary kinetic salt effect, the ionization of a neutral species increases as the ionic strength of a solvent increases (Bronsted and Teeter, 1925). Such an effect would cause the deprotonation of acids to increase as ionic strength increases. The secondary kinetic salt effect would allow more of the photoproduced aci-TNT species to proceed to products and not reform TNT, resulting in an increase in the rate of TNT disappearance. The ionic strength of the artificial seawater solutions used herein varied from 0.01 to $0.7 \mathrm{M}$. When using apparent quantum yields in place of rate constants, the apparent quantum yields of TNT in artificial seawater solutions of varying ionic strengths (measured in the absence of added fulvic acid) follow a linear trend with increasing ionic strength or salinity, S, raised to the $1 / 2$ power: 


$$
\begin{aligned}
& \left(\frac{\phi}{\phi_{o}}\right)=29 \mu^{1 / 2}-0.75 \\
& \left(\frac{\phi}{\phi_{o}}\right)=4.01 \mathrm{~S}^{1 / 2}+0.664
\end{aligned}
$$

These fits are good with $\mathrm{R}^{2}=0.999$ as demonstrated in Fig. 3B for salinity, lending support to the idea that the secondary kinetic salt effect is the controlling factor under the experimental conditions studied herein. In this instance, the direct photolysis reaction is not changed because the aci-TNT species produced by direct photolysis is unchanged, only the subsequent reaction of the aci-TNT species is changed.

\subsubsection{Impact of dissolved organic matter on photolysis rates}

Increasing the fulvic acid concentration from 0 to $5.0 \mathrm{mg} / \mathrm{L}$ increases the first order rate constant for the photolysis of TNT in ultrapure water and artificial seawater solutions at varying salinities (Table 2). The impact is the greatest for ultrapure water where an increase of fulvic acid from 0 to $5 \mathrm{mg} / \mathrm{L}$ results in an increase in the rate constant for the photolysis of TNT from 0.03 to $0.12 \mathrm{~h}^{-1}$. For higher salinity solutions, the impact is not as great. In artificial seawater with a salinity of 15 , the increase is only from 0.049 to $0.54 \mathrm{~h}^{-1}$ for the same increase in fulvic acid. Luning Prak et al. (2013) also saw that the addition of fulvic acid increased the rate of photolysis of 2,4-DNT and 2,6-DNT in ultrapure water more than in waters with higher salinity. Such an increase in the rate constant suggests that the fulvic acid may be acting as a "catalyst" or "sensitizer" in the TNT photoreaction as has been found for other nitroaromatic compounds (Simmons and Zepp, 1986). Zepp et al. (1985) have shown that the humic substances can act as triplet sensitizers in photoreactions. Mabey et al. (1983) provided evidence that humic acid could act as a triplet sensitizer in TNT photolysis. They found that TNT photolysis in pure water under 
nitrogen purged conditions (oxygen removed) had a first-order rate constant that was higher than in the presence of oxygen, and they attributed the change to oxygen acting as a triplet-excited state quencher. Humic substances can also increase the rate of reactions by the formation of other species, such as hydroxyl radicals (Liefer, 1988). In the current study, a hydroxyl radical scavenger was used to show that hydroxyl radical reactions are not playing a significant role in the photolysis of TNT under the conditions studied herein. Details on this test can be found in the Supplementary Material.

\subsubsection{Correlation of rate constant to salinity and fulvic acid concentration}

A correlation was developed to incorporate the dependence of the TNT transformation rate constant on the concentration of fulvic acid $\left(\mathrm{C}_{\mathrm{FA}}, \mathrm{mg} \cdot \mathrm{L}^{-1}\right)$ and salinity in the form

$$
\mathrm{k}_{\text {predicted }}=0.03 \mathrm{~S}^{\prime}+A(\text { Salinity })^{0.5} \mathrm{~S}^{\prime}+B \mathrm{C}_{\mathrm{FA}}\left(\mathrm{mg} \cdot \mathrm{L}^{-1}\right)
$$

where $A$ and $B$ are fitting parameters, $\mathrm{S}^{\prime}$ is the screening factor (eq. 3). The dependence of the screening factor on fulvic acid concentration was determined using absorbance measurements from the artificial seawater and ultrapure water systems with and without added fulvic acid:

$$
\mathrm{S}^{\prime}=-0.0478 \mathrm{C}_{\mathrm{FA}}\left(\mathrm{mg} \cdot \mathrm{L}^{-1}\right)+0.989
$$

This relation is shown in the Supplementary Material. The rate constants from the MilliQ and artificial seawater experiments (Table 2) were fit to eq. (12) using the GRG nonlinear engine of the SOLVER function in Microsoft Excel 2010 to minimize the sum of the square of the difference between the model and the corrected rate constant from the data:

$$
\min \Sigma(\text { model }- \text { experimental data })^{2}
$$

The best fit correlation was

$$
\mathrm{k}_{\text {measured }}=0.003 \mathrm{~S}^{\prime}+0.013(\text { Salinity })^{0.5} \mathrm{~S}^{\prime}+0.026 \mathrm{C}_{\text {fulvic acid }}\left(\mathrm{mg} \cdot \mathrm{L}^{-1}\right)
$$


with a coefficient of determination, $\mathrm{R}^{2}$, of 0.965 . A plot of the correlated rate constant is given in Fig. 4.

The predictive behavior of eq. (15) was tested using these seawater and estuary water samples. To use eq. (15) to predict the TNT transformation rate constant for different natural water types, the equivalent concentration of fulvic acid needs to be estimated. Two approaches were taken to estimate the equivalent fulvic acid concentration. In the first method, it was assumed that all the measured dissolved organic carbon (DOC) is fulvic acid, and that fulvic acid is $52.44 \%$ carbon by mass (IHSS). This value would be an upper limit on fulvic acid concentration, because usually less than half of the organic carbon in natural water is fulvic acid (Thurman, 1985). These estimated fulvic acid concentrations are given in Table 3 . The second method used to estimate the fulvic acid concentration employed the values of absorbance at 320 , 340 , and $360 \mathrm{~nm}$, which are within the range of 295 to $395 \mathrm{~nm}$ wavelengths that are being investigated in this study. The absorbance values of ultrapure water at these wavelengths are linearly related to the fulvic acid concentration as given in the Supplementary Material. These linear relationships were used to estimate the amount of fulvic acid in the samples for each wavelength, and an average of those values is given in Table 3. These estimates of fulvic acid concentration are lower than those estimated by the first method, except for the Charleston water samples, which are a little higher. This result is expected since the first method gives an upper bound to fulvic acid concentration. Simmons and Zepp (1986) also used optical properties to match natural river water samples from Georgia and Florida with solutions they had prepared using fulvic acid isolated from a Georgia river. Using this method, they found that 2,6-DNT photolysis enhancement was the same for the natural water samples and the optically matched solutions containing fulvic acid. They concluded that non-humic organic components of the 
natural fresh waters they tested had no more than a minor effect on nitroaromatic

photochemistry. We have shown herein how both inorganic compounds and fulvic acid affect

photochemistry.

The predictions of the TNT photolysis rate constants for the natural waters studied here are given in Table 3 based on the two estimates for fulvic acid concentration from DOC and absorbance measurements. Both methods predict the rate constant fairly well (compare right three columns of Table 3). The prediction of the rate constants for TNT photolysis in the seawater samples are all predicted well, except for Charleston Estuary water, which is underpredicted by both methods. The success of this approach suggests that such correlations can be used to estimate the rate constant for TNT photolysis in natural waters at $20{ }^{\circ} \mathrm{C}$ with a measurement of salinity and dissolved organic matter.

\subsection{Reaction product isolation and identification}

When TNT is photolyzed, many products are formed, but many of these compounds are not commercially available nor readily synthesized at a reasonable cost. In this study, four compounds that are commercially available and that are formed by the photolysis of TNT in pure water and river water (Burlinson et al. 1979; Burlinson, 1980; Godejohann et al., 1998) were isolated and identified from solutions of seawater containing TNT that were photolyzed. These compounds were 1,3,5-trinitrobenzene (TNB), 2,4,6-trinitrobenzaldehyde (TNBCHO), 2,4,6trinitrobenzoic acid (TNBCOOH), and 2-amino 4,6-dinitrobenzoic acid (2A46DNBA). The exact mechanism by which photolysis occurs is not known, but what is generally believed is shown in Fig. 5. 
Extraction of seawater solutions containing $0.089 \mathrm{mM}$ TNT before and after photolysis showed the formation of TNBCHO and TNB (extracted using a C-18 cartridge and eluted with water) as well as TNBCOOH and 2A46DNBA (extracted using an HLB extraction cartridge and eluted with methanol) from the photolysis process. The presence of these products was confirmed by matching the retention times and MS/MS spectrometry of the pure compound with those of components in the mixture. Prior to photolysis, TNT (retention time $22.7 \mathrm{~min}$, compound "C") was present but not the four products, as shown by the dashed-dotted line in Figure $6 \mathrm{~A}$ and $6 \mathrm{~B}$. TNBCHO, labeled as "E" at an 11 min retention time, forms within one hour of photolysis (solid line), but then photodegrades away to a lower concentration at 6 hours (dashed line Figure 6A). TNBCHO photosensitivity was also reported by Burlinson et al. (1979) in fresh water systems. TNB, labeled as "D" at $12.1 \mathrm{~min}$, also forms within one hour of photolysis, but its concentration is higher at 6 hours, indicating that it is accumulating. Both of these products have been hypothesized to come from TNBOH (Fig. 5). 2A46TNBA, labeled as "F" at $11.1 \mathrm{~min}$, and $\mathrm{TNBCOOH}$, labeled as "G" at $8.8 \mathrm{~min}$, were present in measurable quantities only after 6 hours of photolysis (Figure 6B). Researchers have suggested that 24ADNTBA is formed from TNBOH, while the intermediates in TNBCOOH formation are not known (Fig. 5).

The transformation of TNT in seawater to these four photolysis products was found to be similar to that in pure water, but the photolysis rates in sweater were faster. A photolysis time of 17 hours was needed before these products could be detected in water. The amount of material converted from TNT into each product in seawater solutions only differs slightly from that in pure water. After the 6-hours irradiation, 9\% of the TNT had been converted into 2A46DNBA and $0.2 \%$ had been converted in $\mathrm{TNBCOOH}$. These percentages are slightly less than the $11 \%$ 
and $1 \%$ conversion values reported for the photolysis of TNT in pure water into 2A46DNBA and TNBCOOH, respectively (Burlinson et al., 1979). In seawater, 6.5\% of the TNT is converted into TNBCHO after 30 minutes, which is slightly less than the 8 to $10 \%$ conversion reported for the photolysis of TNT in pure water (Burlinson et al., 1979). TNBCHO's concentration after 6 hours was less due to its photosensitivity. After 6-hours, $2 \%$ of the TNT in seawater had been converted into $\mathrm{TNB}$, which is slightly more than the reported 0.5 to $1 \%$ conversion for pure water systems (Burlinson et al., 1979). The TNB was not photosensitive, and its concentration was higher after 6 hours than after 1 hour.

The lack of photosensitivity of the TNT photoproducts can result in their accumulation in the environment if they are not transformed by other means. Since the products are formed faster in saline waters, they have more of an opportunity to reach higher levels of concentration, especially if isolated on beaches or estuary systems with little mixing, and can have a greater negative impact on various organisms. TNB, which we found to increase in concentration over time in this work and to not to be photoreactive when irradiated by itself (Luning Prak, 2012A), has been reported to be a "direct acting mutagen, causing both frameshift and base-pair mutations" (Inouye et al., 2009). In a summary given by Nipper et al. (2009) on the impact of TNB on aquatic organisms, the toxicity ranged from 0.06 to $296 \mu \mathrm{M}$ TNB for freshwater fish, invertebrates, microalgae, and bacteria. For marine organisms, the most sensitive test reported was a 96-hr zoospore germination test with green macroalga that had an $\mathrm{EC}_{50}$ of $0.38 \mu \mathrm{M}$. For the 2A46DNBA and TNBA, research on their genotoxicity showed that both compounds induced significant mutations in bacterial and human cells (Grummt et al., 2006). Comparisons of the toxicity predicted by Mictrotox ${ }^{\circledR}$ and ECOSAR, a predictive tool used by the Office of Pollution Prevention and Toxics at the U. S. Environmental Protection Agency, show that Mictrotox ${ }^{\circledR}$ 
assigns the same toxicity level to TNBA as TNT, but ECOSAR assigns a higher toxicity to TNBA (Cash, 1998).

\subsection{Conclusions}

This study sought to determine the impact of salinity, $\mathrm{pH}$, temperature, and dissolved organic matter on the rate of photolysis of 2,4,6-trinitrotoluene in marine, estuarine, and laboratory-prepared waters and to isolate and confirm the presence of some products formed in marine waters. Varying $\mathrm{pH}(6.4$ to 8.1$)$ and temperature $\left(10\right.$ to $\left.32^{\circ} \mathrm{C}\right)$ over the range of values found in marine waters produced TNT photolysis rate constants that did not change significantly with $\mathrm{pH}$, which has also been found for 2,4-DNT and 2,6-DNT, and that increased slightly with increasing temperature. The activation energy was determined to be $12.3 \pm 0.3 \mathrm{~kJ} / \mathrm{mol}$, which is within the values reported for other photochemical reactions. Increasing the salinity of the water increased the first-order photolysis rate constant and the apparent quantum yield. The secondary kinetic salt effect can explain this behavior. In the secondary kinetic salt effect, the protonation of anions to form acids decreases as ionic strength increases, so more anions are available to participate in other reactions. Researchers have found that the photolysis of TNT forms an aciTNT species that rapidly forms a TNT anion, which can react with hydrogen ions to reform TNT (Burlinson et al., 1979B). Reducing the reaction with hydrogen under conditions of higher ionic strength allows the anion to form products instead of reforming TNT, with the net effect of a higher transformation rate of TNT. With a secondary kinetic salt effect, the salts are not acting as a sensitizer through an indirect photolysis mechanism, but are stabilizing a product from the direct reaction that prevents it from reforming TNT.

The addition of dissolved organic matter (up to $5 \mathrm{mg} / \mathrm{L}$ ) to ultrapure water, artificial seawater, and natural seawater enhanced the photolysis of TNT and increased its rate constant. 
The addition of fulvic acid to ultrapure water increased the TNT photolysis rate constant more than when added to artificial seawater, which is similar to the behavior of 2,4-DNT and 2,6-DNT photolysis. Humic material such as fulvic acid can enhance the photolysis by acting as a triplet sensitizer. A correlation was developed for the rate constant for photolysis based on salinity of artificial seawater and added dissolved fulvic acid. This correlation successfully predicted the rate constants in natural seawater and estuary waters. These results show that the presence of ionic substances and fulvic acids can enhance the transformation of TNT in natural waters and reduce the toxicity posed by TNT itself. Products formed by TNT photolysis in natural seawater, 2,4,6-trinitrobenzaldehyde, 1,3,5-trinitrobenzene, 2,4,6-trinitrobenzoic acid, and 2-amino 4,6dinitrobenzoic acid, were the same as those found in ultrapure water, though they were produced more quickly. This shows that some of the mechanisms that operate in freshwater systems also operate in seawater. The products formed during photolysis are also toxic and the ultimate impact on a seawater/estuary system depends on whether they accumulate or are transformed by other processes in the environment.

\section{Acknowledgments}

The authors wish to thank Mr. Matt Schroeder for his help in HPLC maintenance.

Funding for this research came from the Defense Threat Reduction Agency, the Office of Naval Research, and the Strategic Environmental Research and Development Program, grant \# ER2123. These funding sources were not involved in the study design; in collection, analysis and interpretation of data; in the writing of the report; or in the decision to submit the article for publication. 


\section{References}

Baltrop, J. A., Coyle, J. D., 1975. Excited states in organic chemistry. John Wiley and Sons: New York, Chapter 5.

Bronsted, J.N., Tetter, C.E., 1924. On kinetic salt effect. J. Phys. Chem. 28, 579-587.

Burlinson, N.E., Sitzmann, M.E., Glover, D.J., Kaplan, L.A., 1979.Photochemistry of TNT and related nitroaromatics: part III. Naval Surface Weapons Center, Report number NSWC WOL TR 78-198. (Silver Spring, MD).

Burlinson, N.E, Sitzmann, M.E., Kaplan, L.A., Kayser, E., 1979B. Photochemical generation of the 2,4,6-trinitobenzyl anion. J. Org. Chem. 44, 3695-3698.

Burlinson, N.E., 1980. Fate of TNT in an aquatic environment: photodecomposition vs biotransformation. Naval Surface Weapons Center, Report number NSWC TR 79-445. (Silver Spring, MD).

Cash, G. G., 1998. Prediction of chemical toxicity to aquatic organisms: ECOSAR vs. Mictrotox ${ }^{\circledR}$ Assay, Environ. Toxicol. Water Qual. 13, 211-216.

Celin, S.M., Pandit, M., Kapoor, J.C., Sharma, R.K., 2003. Studies of photo-degradation of 2,4dinitrotoluene in aqueous phase. Chemosphere 53, 63-69.

Fowler, R., Guggenheim, E. A. 1960. Statistical Thermodynamics. Cambridge at the University Press, London, pp. 536-540.

International Humic Substances Society, Elemental Compositions and Stable Isotopic Ratios of IHSS Samples, http://www.humicsubstances.org/elements.html

Godejohann, M., Astratov, M., Preiss, A., Levsen, K., Mugge, C., 1998. Application of continuous-flow HPLC-proton-nuclear magnetic resonance spectroscopy and HPLCthermospray-mass spectrometry for the structural elucidation of phototransformation products of 2,4,6-trinitrotoluene. Anal. Chem.70, 4104-4110.

Grummt, T., Wunderlich, H.-G., Chakraborty, A., Kundi, M., Majer, B., Ferk, F., Nersesyan, A., Parzefall, W., Knasmuller, S., 2006. Genotoxicity of nitrosulfonic acids, nitrobenzoic acids, and nitrobenzylalcohols, pollutants commonly found in groundwater near ammunition facilities. Environmental and Molecular Mutagenesis 47, 95-106.

Inouye, L., Lachance, B., Gong, P., 2009, Genotoxicity of Explosives, in: Sunahara, G. I., Lotufo, G., Kuperman, R. G.,Hawari, J. (Eds.), Ecotoxicology of explosives. CRC Press, Boca Raton, FL., pp. 184. 
Johannessen, S. C., Miller, W. L., 2001. Quantum yield for the photochemical production of dissolved inorganic carbon in seawater, Marine Chemistry 76, 271-283.

Leifer, A. 1998. The Kinetics of Environmental Aquatic Photochemistry (ACS Professional Reference Books). American Chemical Society, Washington, DC.

Luning Prak, D.J., Milewski, E.A., Jedlicka, E.E., Kersey, A.J., O’Sullivan, D.W., 2013. Influence of $\mathrm{pH}$, temperature, salinity, and dissolved organic matter on the photolysis of 2,4dinitrotoluene and 2,6-dinitrotoluene in seawater. Mar. Chem. 157, 233-241.

Luning Prak, D.J., Gordon, K.C., Peterson, J.M., O’Sullivan, D.W., 2012. Photolysis of dinitrobenzyl alcohols, dinitrobenzaldehydes, and nitrobenzoic acids in seawater, estuary water, and pure water. Mar. Chem. 145-147, 29-36.

Luning Prak, D. J., 2012A, Photochemical transformation of munitions constituents in marine waters, reported submitted to the Strategic Environmental Research and Development Program, SERDP Project \# ER-2123.

Mabey, W.R., Tse, D., Baraze, A., Mill T., 2003. Photolysis of nitroaromatics in aquatic systems: 2,4,6-trinitrotoluene. Chemosphere 12, 3-16.

Montgomery, M.T., Coffin, R.B., Boyd, T.J., Obsurn, C.L., 2012. TNT Biodegradation by Natural Microbial Assemblages at Estuarine Frontal Boundaries, Naval Research Laboratory Report \# NRL/MR/6110-12-9390 (July).

Mihas, O., Kalogerakis, N., Psillakis, E., 2007. Photolysis of 2,4-dinitrotoluene in various water solutions: effect of dissolved species. J. Hazard Mater. 146,535-539.

Millero, F.J., 2006. Chemical Oceanography. $3^{\text {rd }}$ ed. CRC Press, Taylor and Francis Group, Boca Raton, FL.

Nima, C., Frette, E., Hamre, B., Erga, S.R., Chen, Y.-C., Zhao, L., Sørensen, K., Norli, M., Stamnes, K., Stamnes, J.J., 2016. Absorption properties of high-latitude Norwegian coastal water: The impact of CDOM and particulate matter. Estuar. Coast. Shelf Sci., doi: 10.1016/ j.ecss.2016.05.012

Nipper, M., Carr, R.S., Lotufo, GR., 2009. Aquatic toxicology of Explosives, in: Sunahara, G. I., Lotufo, G., Kuperman, R. G.,Hawari, J. (Eds.), Ecotoxicology of explosives. CRC Press, Boca Raton, FL., pp. 77-115.

Nipper, M., Qian, Y., Carr, R.S., Miller, K., 2004. Degradation of picric acid and 2,6-DNT in marine sediments and water: the role of microbial activity and ultra-violet exposure.

Chemosphere 56, 529-530. 
O’Sullivan, D.W., Denzel, J.R., Luning Prak, D.J., 2010. Photolysis of 2,4-dinitrotoluene and 2,6-dinitrotoluene in seawater. Aquat. Geochem. 16, 491-505.

O’Sullivan, D.W., Denzel, J.R., Luning Prak, D.J., 2011. Photolysis of 2,4,6-Trinitrotoluene in Seawater: Effect of salinity and nitrate concentration. In: Chappell, M.A., Price, C.L., George, R.G. (Eds.), Environmental Chemistry of Explosives and Propellant Compounds in Soils and Marine Systems: Distributed Source Characterization and Remedial Technologies. ACS Symposium Series 1069. American Chemical Society, Washington, DC, pp. 157-169.

Sandus, O., Slagg, N., 1972, Reactions of aromatic nitrocompounds. I. Photochemistry, U.S. NTIS, AD Report, AD-753923, 48 pp.

Sunahara, G.I., Kuperman, R. C., Lotufo, G.R, Hawari, J., Thiboutot, S., Ampleman, G., 2009 Introduction. In: Sunahara, G. I., Lotufo, G. R., Kuperman, R. C., Hawari, J. (Eds.), Ecotoxicology of explosives. CRC Press, Boca Raton, FL, pp. 1-2.

Simmons, M.S., Zepp, R.G., 1986. Influence of humic substances on photolysis of nitroaromatic compounds in aqueous systems. Water Res. 20, 899-904.

Suryanarayanan, K., Capellos, C., 1974. Flash photolysis of 2,4,6-trinitrotoluene solutions. Int. J. Chem. Kinetics 6, 89-102.

Thurman, E. M., 1985, Organic Geochemistry of Natural Waters, Martinu Nijhoff/Dr. W. Junk Publishers, Drodrecht.

Zepp, R.G., Schlotzhauer P.F., Sin, R.M., 1985. Photosensitized transformations involving electronic energy transfer in Natural waters: role of humic substances. Environ. Sci. Technol. 19: 74-81. 


\begin{tabular}{|c|c|c|c|c|c|c|}
\hline \multirow{2}{*}{$\begin{array}{l}{[\mathrm{TNT}]} \\
(\mathrm{mM})\end{array}$} & \multirow{2}{*}{$\begin{array}{l}\text { Seawater or estuary } \\
\text { water }\end{array}$} & \multirow[t]{2}{*}{ Salinity } & \multirow{2}{*}{$\begin{array}{l}\mathrm{DOC}^{\mathrm{a}} \\
(\mathrm{mg} \\
\left.\mathrm{C} \cdot \mathbf{L}^{-1}\right)\end{array}$} & \multicolumn{3}{|c|}{ Long-pass filters wavelength } \\
\hline & & & & $295 \mathrm{~nm}$ & $395 \mathrm{~nm}$ & $\begin{array}{l}\text { Dark } \\
\text { Control }\end{array}$ \\
\hline 0.089 & Charleston & $33 \pm 1$ & 0.94 & $0.48 \pm 0.03$ & 0.03 & $\mathrm{NC}$ \\
\hline 0.089 & Gulf (New Orleans) & $31 \pm 1$ & 0.91 & $0.54 \pm 0.06$ & 0.07 & $\mathrm{NC}$ \\
\hline 0.081 & Hawaii & $31 \pm 1$ & 0.97 & $0.50 \pm 0.02$ & 0.03 & $\mathrm{NC}$ \\
\hline 0.087 & Key West & $32 \pm 1$ & & $0.58 \pm 0.03$ & 0.02 & $\mathrm{NC}$ \\
\hline 0.023 & Key West & $32 \pm 1$ & & $0.92 \pm 0.03$ & 0.03 & $\mathrm{NC}$ \\
\hline 0.047 & Key West & $32 \pm 1$ & & $0.75 \pm 0.04$ & 0.02 & $\mathrm{NC}$ \\
\hline 0.045 & Diluted Key West seawater & $24 \pm 1$ & & $0.67 \pm 0.01$ & $0.02^{b}$ & $\mathrm{NC}$ \\
\hline 0.045 & Diluted Key West seawater & $16 \pm 1$ & & $0.55 \pm 0.04$ & 0.02 & $\mathrm{NC}$ \\
\hline 0.045 & Diluted Key West seawater & $8.4 \pm 1$ & & $0.37 \pm 0.01$ & 0.01 & $\mathrm{NC}$ \\
\hline 0.048 & Charleston & $33 \pm 1$ & 0.94 & $0.75 \pm 0.03$ & 0.03 & $\mathrm{NC}$ \\
\hline 0.045 & Gulf (New Orleans) & $31 \pm 1$ & 0.91 & $0.73 \pm 0.04$ & 0.03 & $\mathrm{NC}$ \\
\hline 0.041 & Hawaii & $31 \pm 1$ & 0.97 & $0.70 \pm 0.03$ & 0.01 & $\mathrm{NC}$ \\
\hline 0.048 & Charleston Harbor & $22 \pm 1$ & 1.86 & $0.65 \pm 0.02$ & 0.02 & $\mathrm{NC}$ \\
\hline 0.048 & Charleston Estuary & $5.2 \pm 1$ & 4.6 & $0.39 \pm 0.01$ & 0.01 & $\mathrm{NC}$ \\
\hline 0.048 & Alaska & $9.9 \pm 1$ & & $0.45 \pm 0.01$ & 0.01 & $\mathrm{NC}$ \\
\hline 0.047 & Mississippi & $10.1 \pm 1$ & 3.53 & $0.54 \pm 0.01$ & 0.03 & $\mathrm{NC}$ \\
\hline 0.044 & Annapolis, MD & $6.5 \pm 1$ & & $0.35 \pm 0.01$ & 0.01 & $\mathrm{NC}$ \\
\hline
\end{tabular}

Error is the standard error of the slope from the regression of eq. 1.

$\mathrm{NC}$ is no significant change in concentration.

(a) taken from Luning Prak et al. (2013) and Montgomery et al. (2012). (b) Estimated based on 16 and 32 ppm salinity values 
Table 2. Rate constants $\mathrm{k}\left(\mathrm{hr}^{-1}\right)$, apparent quantum yields ${ }^{\mathrm{a}} \phi_{\text {apparent, }}$ and fitted apparent quantum yields from eq. (10) for the photolysis of TNT in pure water and artificial seawater with added Suwanee River fulvic acid at $20^{\circ} \mathrm{C}$.

\begin{tabular}{|c|c|c|c|c|c|c|}
\hline & $\begin{array}{l}\text { Fulvic } \\
\text { acid } \\
(\mathrm{mg} / \mathrm{L})\end{array}$ & $\begin{array}{l}\text { TNT } \\
\text { Initial } \\
(\mathrm{mM})\end{array}$ & $\begin{array}{l}295 \mathrm{~nm} \\
\mathrm{k}\left(\mathrm{hr}^{-1}\right)\end{array}$ & $\begin{array}{l}395 \mathrm{~nm} \\
\mathrm{k}\left(\mathrm{hr}^{-1}\right)\end{array}$ & $\phi_{\text {apparent }}$ & $\begin{array}{l}\text { Fitted } \\
\mathrm{k}\left(\mathrm{hr}^{-1}\right) \text { from } \\
\text { eq. (15) }\end{array}$ \\
\hline \multirow[t]{4}{*}{ MilliQ } & 0 & & 0.03 & $\mathrm{NC}$ & \multirow[t]{4}{*}{0.0026} & 0.03 \\
\hline & 0.5 & 0.047 & $0.045 \pm 0.004$ & $\mathrm{NC}$ & & 0.039 \\
\hline & 1 & 0.044 & $0.072 \pm 0.008$ & $\mathrm{NC}$ & & 0.052 \\
\hline & 5 & 0.045 & $0.12 \pm 0.01$ & $\mathrm{NC}$ & & 0.15 \\
\hline \multirow{4}{*}{$\begin{array}{l}\text { Art SW } \\
S=0.7\end{array}$} & 0 & 0.043 & $0.10 \pm 0.01$ & $\mathrm{NC}$ & \multirow[t]{4}{*}{0.0072} & 0.14 \\
\hline & 0.5 & 0.044 & $0.13 \pm 0.01$ & $\mathrm{NC}$ & & 0.15 \\
\hline & 1 & 0.045 & $0.15 \pm 0.01$ & $\mathrm{NC}$ & & 0.16 \\
\hline & 5 & 0.043 & $0.17 \pm 0.01$ & $\mathrm{NC}$ & & 0.24 \\
\hline \multirow{4}{*}{$\begin{array}{l}\text { Art SW } \\
S=1.5\end{array}$} & 0 & 0.043 & $0.15 \pm 0.01$ & $\mathrm{NC}$ & \multirow[t]{4}{*}{0.011} & 0.19 \\
\hline & 0.5 & 0.043 & $0.20 \pm 0.01$ & $\mathrm{NC}$ & & 0.20 \\
\hline & 1 & 0.044 & $0.19 \pm 0.01$ & $\mathrm{NC}$ & & 0.20 \\
\hline & 5 & 0.044 & $0.25 \pm 0.01$ & $\mathrm{NC}$ & & 0.27 \\
\hline \multirow{4}{*}{$\begin{array}{l}\text { Art SW } \\
S=3.1\end{array}$} & 0 & 0.046 & $0.22 \pm 0.01$ & 0.003 & \multirow[t]{4}{*}{0.016} & 0.26 \\
\hline & 0.5 & 0.046 & $0.30 \pm 0.01$ & 0.005 & & 0.26 \\
\hline & 1 & 0.045 & $0.29 \pm 0.01$ & 0.01 & & 0.27 \\
\hline & 5 & 0.045 & $0.37 \pm 0.01$ & 0.01 & & 0.33 \\
\hline \multirow{4}{*}{$\begin{array}{l}\text { Art SW } \\
S=7.5\end{array}$} & 0 & 0.042 & $0.38 \pm 0.01$ & $\mathrm{NC}$ & \multirow[t]{4}{*}{0.028} & 0.38 \\
\hline & 0.5 & 0.048 & $0.40 \pm 0.01$ & 0.01 & & 0.39 \\
\hline & 1 & 0.048 & $0.46 \pm 0.01$ & 0.01 & & 0.39 \\
\hline & 5 & 0.048 & $0.47 \pm 0.01$ & 0.070 & & 0.42 \\
\hline \multirow{4}{*}{$\begin{array}{l}\text { Art SW } \\
S=15\end{array}$} & 0 & 0.049 & $0.49 \pm 0.02$ & 0.01 & \multirow[t]{4}{*}{0.039} & 0.53 \\
\hline & 0.5 & 0.049 & $0.56 \pm 0.02$ & 0.01 & & 0.53 \\
\hline & 1 & 0.049 & $0.53 \pm 0.01$ & 0.02 & & 0.53 \\
\hline & 5 & 0.048 & $0.54 \pm 0.01$ & 0.02 & & 0.53 \\
\hline $\begin{array}{l}\text { Art SW } \\
S=30\end{array}$ & 0 & 0.049 & $0.69 \pm 0.04$ & 0.02 & 0.056 & 0.73 \\
\hline
\end{tabular}

Standard error from the slope of the regression

NC, no change. There was no change in the dark controls in any of these experiments. (a) The error in the quantum yield is $15 \%$. 
Table 3. Prediction of the rate constant for TNT for various natural waters using eq. (15) based on estimates of fulvic acid concentrations from dissolved organic carbon measurements and absorbance values at $320 \mathrm{~nm}, 340 \mathrm{~nm}$, and $360 \mathrm{~nm}$

\begin{tabular}{|c|c|c|c|c|c|c|c|c|c|}
\hline & \multirow[b]{2}{*}{ Salinity } & \multirow{2}{*}{$\begin{array}{l}\text { TNT } \\
\text { Initial } \\
(\mathrm{mM})\end{array}$} & \multirow{2}{*}{\multicolumn{2}{|c|}{$\begin{array}{l}\text { From DOC } \\
\text { Estimated } \\
\text { fulvic acid }^{\mathrm{a}} \\
\text { and screeing } \\
\text { factor }^{\mathrm{b}}\end{array}$}} & \multirow{2}{*}{\multicolumn{2}{|c|}{$\begin{array}{l}\text { From absorbance } \\
\text { Estimated fulvic } \\
\text { acid \& screening } \\
\text { factor }^{\mathrm{b}}\end{array}$}} & \multicolumn{2}{|c|}{$\begin{array}{l}\text { Predicted } \mathrm{k}\left(\mathrm{h}^{-1}\right) \\
\text { from Eq. }(15)\end{array}$} & \multirow[t]{2}{*}{$\begin{array}{l}\text { Measured } \\
\mathrm{k}\left(\mathrm{h}^{-1}\right)\end{array}$} \\
\hline & & & & & & & $\begin{array}{l}\text { FA from } \\
\text { DOC }\end{array}$ & $\begin{array}{c}\text { FA from } \\
\text { Absorb- } \\
\text { ance }\end{array}$ & \\
\hline Gulf (New Orleans) & $31 \pm 1$ & 0.045 & 2.2 & 0.88 & 0.42 & 0.97 & 0.72 & 0.74 & $0.73 \pm 0.04$ \\
\hline Hawaii & $31 \pm 1$ & 0.041 & 2.3 & 0.88 & 0.78 & 0.95 & 0.72 & 0.74 & $0.70 \pm 0.03$ \\
\hline Charleston, S.C. & 33 & 0.048 & 1.3 & 0.93 & 1.1 & 0.94 & 0.75 & 0.76 & $0.75 \pm 0.03$ \\
\hline Key West, FL & 32 & 0.047 & & & 1.0 & 0.94 & & 0.75 & $0.75 \pm 0.04$ \\
\hline Charleston Harbor & 22 & 0.048 & 2.2 & 0.88 & 2.8 & 0.86 & 0.62 & 0.62 & $0.65 \pm 0.02$ \\
\hline Charleston Harbor & 5.2 & 0.048 & 10.8 & 0.47 & 3.6 & 0.81 & 0.44 & 0.36 & $0.39 \pm 0.01$ \\
\hline Mississippi Estuary & 10.1 & 0.047 & 8.3 & 0.59 & 2.3 & 0.88 & 0.48 & 0.45 & $0.54 \pm 0.01$ \\
\hline Annapolis, MD & 6.5 & 0.044 & & & 2.0 & 0.89 & & 0.38 & $0.35 \pm 0.01$ \\
\hline Juneau, AK & 10 & 0.048 & & & 0.30 & 0.97 & & 0.44 & $0.45 \pm 0.01$ \\
\hline
\end{tabular}

(a) This estimate is based on assuming that all dissolved organic matter is fulvic acid and that fulvic acid is $52.44 \%$ carbon by mass. This number would be the upper limit on actual fulvic acid because not all organic carbon is fulvic acid. (b) Screening factor is given in equation (3). 

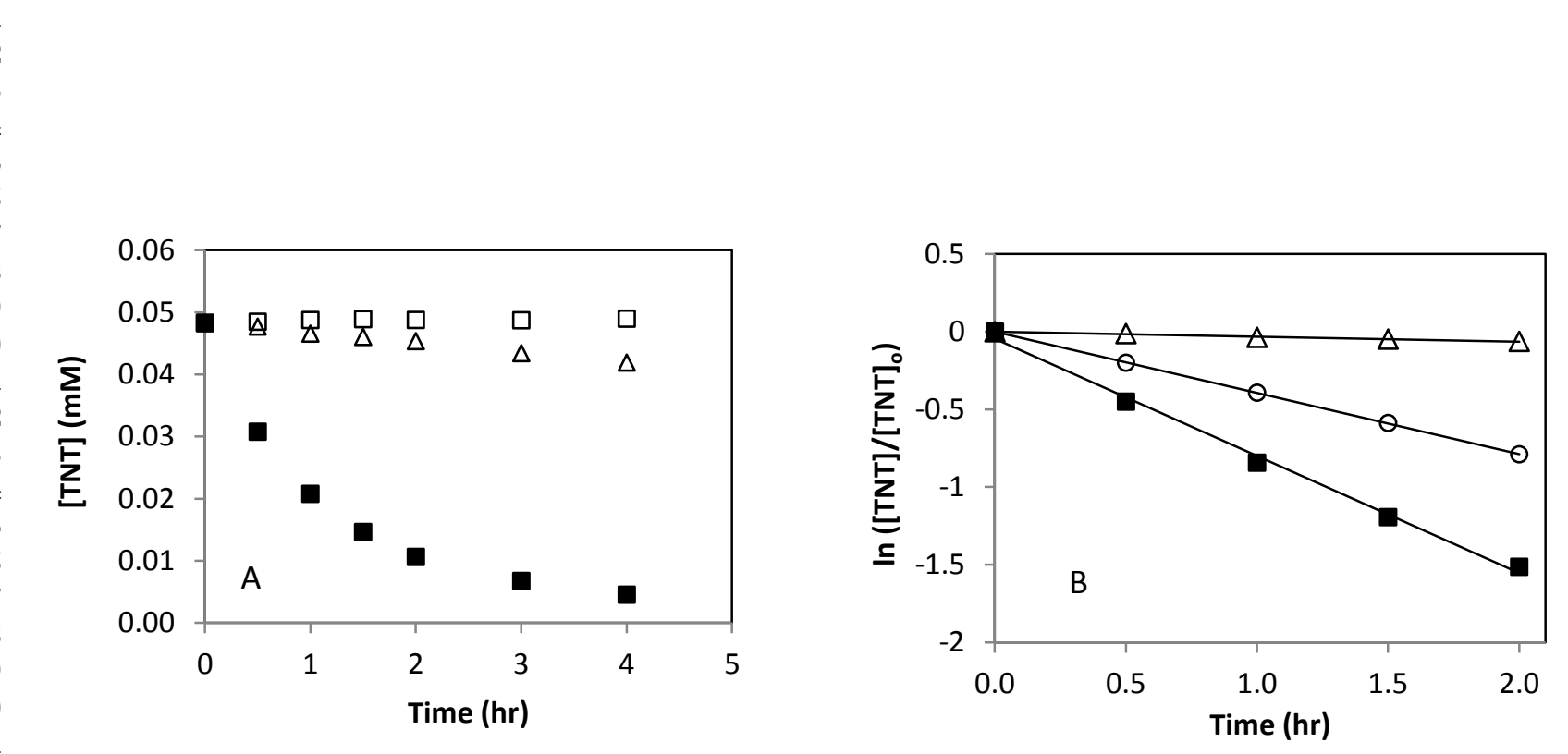

Fig 1. (A) Photolysis of TNT dissolved in filtered Charleston seawater under 295-nm long-pass filter (घ), under 395-nm long-pass filter $(\Delta)$, and in the dark control ( $\square$ ). (B) Determination of first-order rate constant for TNT dissolved in filtered Charleston seawater under 295-nm longpass filter ( $\mathbf{\square})$, under 395-nm long-pass filter $(\Delta)$, and dissolved in Charleston estuary water $(\mathrm{S}=5.2)$ under 295-nm long-pass filter (o). 


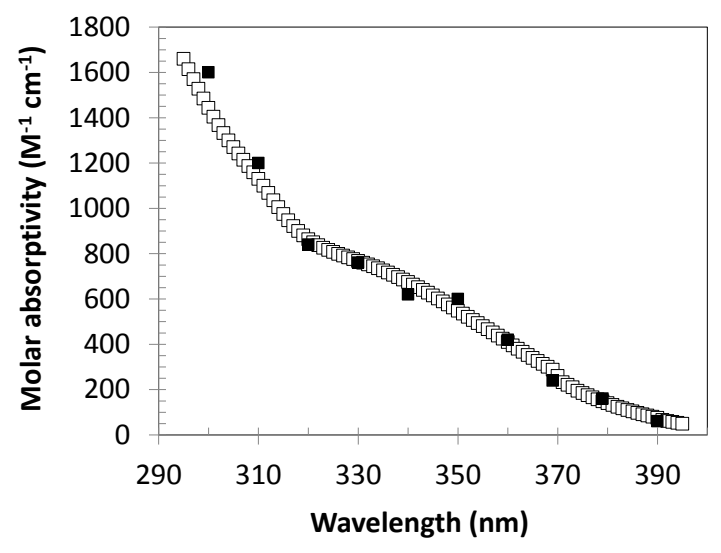

Fig 2. Molar absorptivity of TNT ( $\square$ ) in ultrapure water based on four TNT concentrations ranging from $0.0044 \mathrm{mM}$ to $0.088 \mathrm{mM}$ and two cuvettes $(1-\mathrm{cm}$ and $10-\mathrm{cm})$ and compared with values from Mabey et al., 1983 (ם).
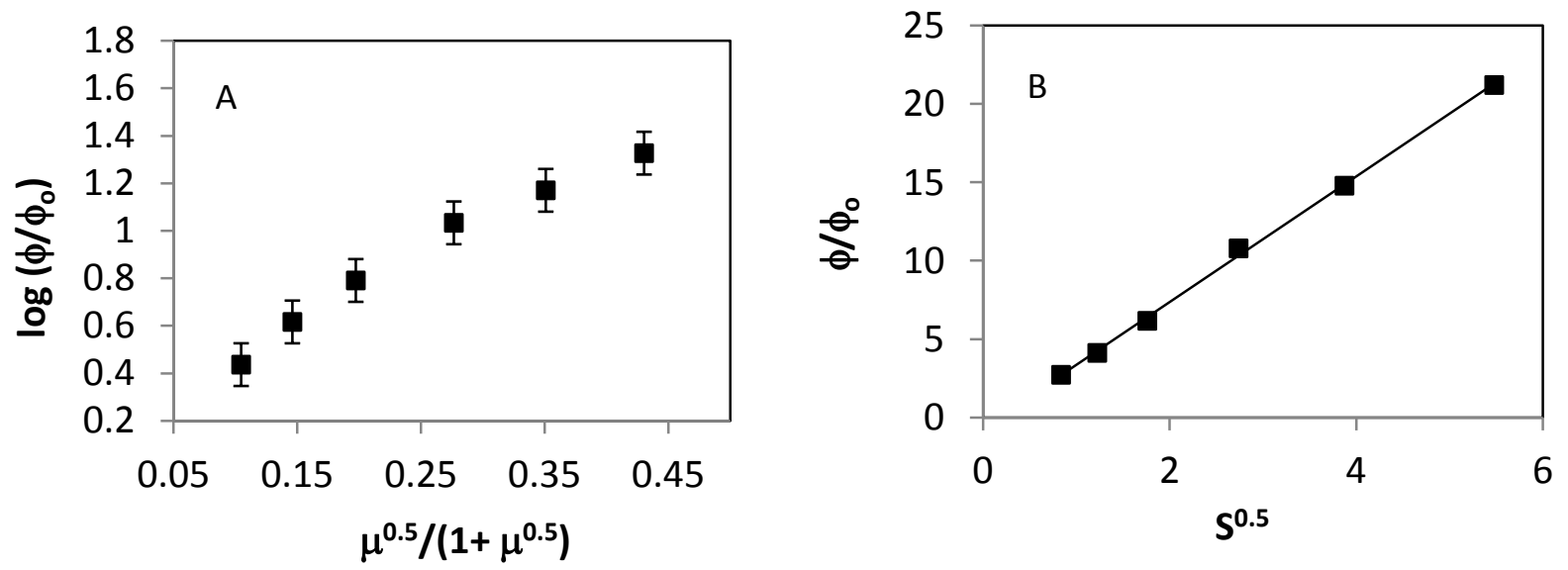

62 
Fig 3. Impact of ionic strength and salinity on the apparent quantum yield of TNT in artificial seawater. (A) A linear functional form of the primary salt effect using the ionic strength would not fit the non-linear behavior of the data. (B) A linear correlation between apparent quantum yield and salinity, $\mathrm{S}$, is good $\left(\mathrm{R}^{2}=0.999\right):\left(\frac{\phi}{\phi_{\mathrm{o}}}\right)=4.01 \mathrm{~S}^{1 / 2}+0.664$. This can be explained by the secondary salt effect.

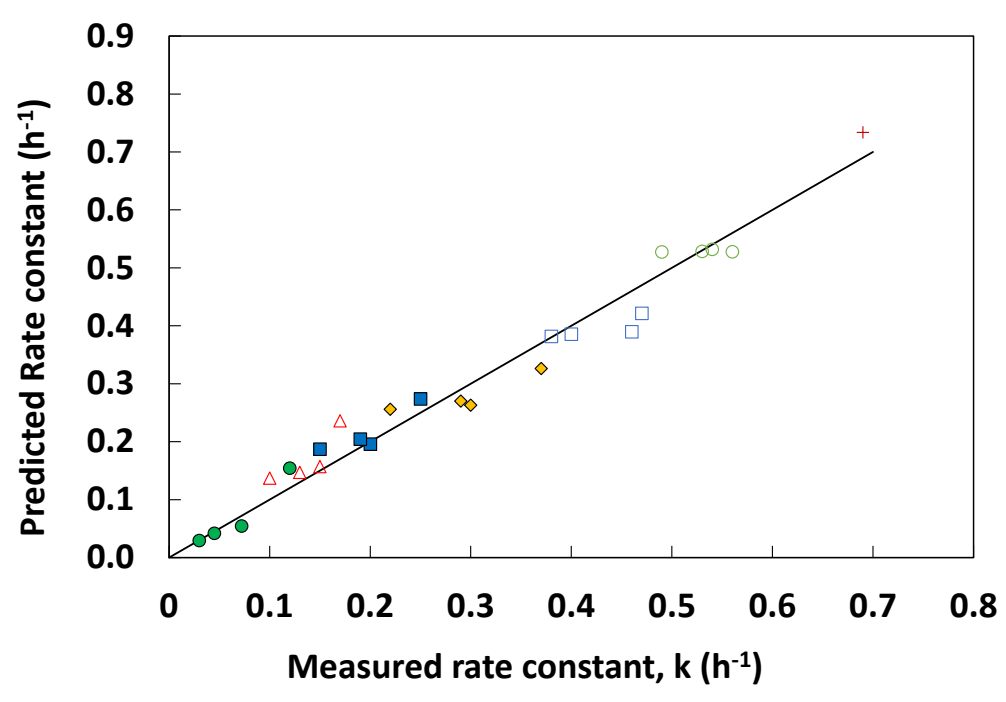

Fig 4. Comparison of measured rate constant and predicted rate constant $\mathrm{k}_{\text {predicted }}$, based on the correlation: $\mathrm{k}_{\text {predicted }}=0.03 \mathrm{~S}^{\prime}+0.013$ (Salinity) ${ }^{0.5} \mathrm{~S}^{\prime}+0.026 \mathrm{C}_{\text {fulvic acid }}\left(\mathrm{mg} \cdot \mathrm{L}^{-1}\right)$ developed from TNT rate constants in ultrapure water $(\bullet)$ and artificial seawater at various concentrations: artificial seawater with salinity $=0.7(\Delta)$, artificial seawater with salinity $=1.5(\square)$; artificial 
seawater with salinity $=3.1(\diamond)$; artificial seawater with salinity $=7.5(\square)$; and artificial seawater with salinity $=15(\circ)$; and artificial seawater with a salinity $=30(+)$. The straight line is used as a guide to indicate the values where the predicted values would exactly match experiment.

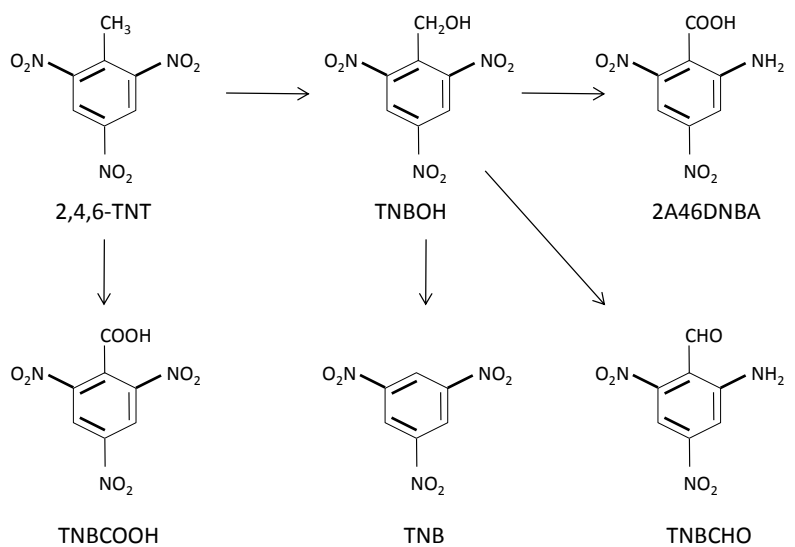

Fig 5. Photodegradation of TNT based on mechanisms proposed in freshwater and ammunition wastewater systems (Godejohann et al., 1998; Burlinson et al., 1979). Abbreviations: 2,4,6trinitrotoluene (2,4,6-TNT), trinitrobenylalcohol (TNBOH), 2-amino-4,6-dinitrobenzoic acid (2A46DNBA), 2,4,6-trinitrobenzoic acid (TNBCOOH), 1,3,5-trinitrobenzene (TNB), and trinitrobenzaldehyde (TNBCHO). 


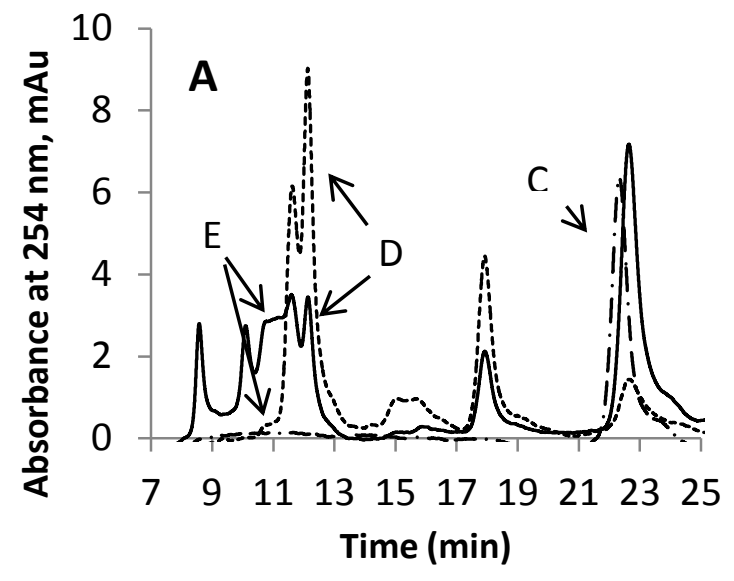

Fig 6. (A) LC chromatograms of $0.089 \mathrm{mM}$ and for 6 hours (dashed line) that were extracted on to a C-18 Sep Pak column and eluted with ultrapure water. C: TNT; D: TNB; E: TNBCHO

(B) LC chromatograms of $0.089 \mathrm{M}$ TNT in Key West seawater unphotolyzed (dash and dotted line) and 6-hour irradiated samples (dashed line) that were acidified to $\mathrm{pH} 3$ and then extracted on to an HLB column and eluted with methanol. A:TNT; D: TNBCOOH; E: 2A46DNBA 


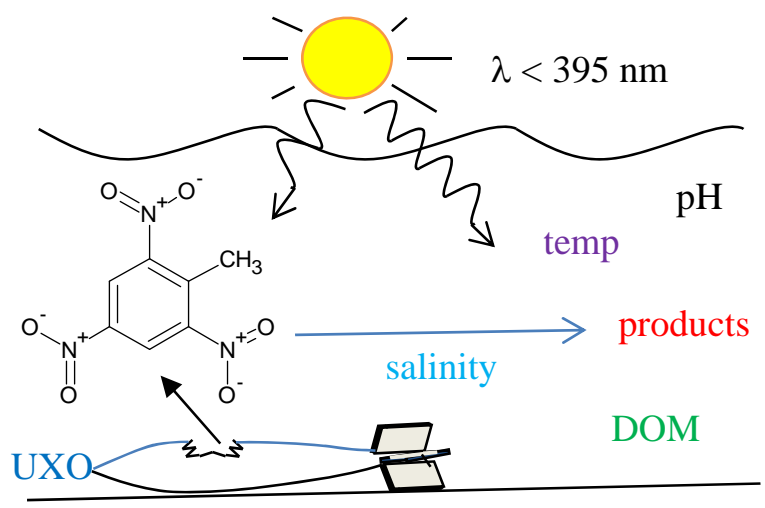

